\title{
Cold tongue/Warm pool and ENSO dynamics in the Pliocene
}

\author{
A. S. von der Heydt, A. Nnafie, and H. A. Dijkstra \\ Institute of Marine and Atmospheric Research Utrecht, Utrecht University, Utrecht, The Netherlands \\ Received: 25 February 2011 - Published in Clim. Past Discuss.: 22 March 2011 \\ Revised: 4 July 2011 - Accepted: 18 July 2011 - Published: 16 August 2011
}

\begin{abstract}
It has been suggested that a "permanent" El Niño climate state has existed in the warm Pliocene. One of the main pieces of evidence of such conditions is the small eastwest sea surface temperature (SST) difference that is found in proxy temperature records of the equatorial Pacific. Using a coupled version of the Zebiak-Cane model of intermediate complexity for the tropical Pacific, we study the sensitivity of the time-mean Pacific background state and El Niño/Southern Oscillation (ENSO) variability to Pliocene climate changes. The parameters varied in this sensitivity study include changes in the trade wind strength due to a reduced equator-to-pole temperature gradient, higher global mean temperatures and an open Panama gateway. All these changes lead to a westward shift of the position of the cold tongue along the equator by up to $2000 \mathrm{~km}$. This result is consistent with data from the PRISM3D Pliocene SST reconstruction. Our model further suggests that ENSO variability is present in the Pliocene climate with only slight changes as compared to today. A background climate that would resemble a "permanent" El Niño with weak to no east-west temperature difference along the equator is only found for very weak trade winds which seem unrealistic for the Pliocene climate.
\end{abstract}

\section{Introduction}

The El Niño/Southern Oscillation phenomenon (ENSO) is one of the strongest and most studied modes of climate variability on interannual time scales. Although the centre of variability is located in the tropical Pacific Ocean, where strong sea surface temperature variations are observed, El Niño affects climate, societies and ecosystems in

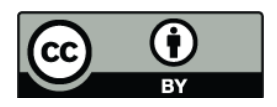

Correspondence to: A. S. von der Heydt (a.s.vonderheydt@uu.nl) many regions of the world (Philander, 1990). The future development of this type of interannual variability remains controversial, mainly because the interaction between long-term mean climate changes and interannual variability is poorly known. State-of-the-art coupled climate models, therefore, predict a variety of changes for ENSO variability under increasing greenhouse gases (Collins, 2005; van Oldenborgh et al., 2005). A promising approach to improve our understanding of the behaviour of ENSO variability under different long-term mean climate states is to study past warm climates. Changes in ENSO variability have been suggested for the early to mid-Pliocene (5.3-3.6 Ma), where global mean temperatures where about $3{ }^{\circ} \mathrm{C}$ higher than today (Ravelo et al., 2004; Dowsett and Robinson, 2009), while estimates of atmospheric greenhouse gas concentrations indicate only about $30 \%$ higher levels than today (Raymo et al., 1996).

Pliocene proxy climate reconstructions mostly have a too coarse temporal resolution to resolve ENSO events, but they are useful to determine the past climatology of the Pacific. Reconstructions of sea surface temperatures (SST) in the western and eastern equatorial Pacific from $\mathrm{Mg} / \mathrm{Ca}$ paleothermometry and $\delta^{18} \mathrm{O}$ records suggest a substantially reduced east-west sea surface temperature (SST) gradient during the early mid-Pliocene (Wara et al., 2005; Dekens et al., 2007). Although there are also contradictory results from the same drilling sites (Rickaby and Halloran, 2005), the small east-west gradient prior to $2.7 \mathrm{Ma}$ has lead to the hypothesis that El Niño-like conditions were a permanent feature of the Pliocene (Fedorov et al., 2006; Ravelo et al., 2006), which is usually referred to as a "permanent" El Niño-like state (Molnar and Cane, 2002). While the proxy data clearly only record the background climate state and are, in general, not able to resolve interannual climate variability, it remains ambiguous from these studies whether the term "permanent El Niño" refers to a climate state with interannual variability around an El-Niño-like mean climate state (Brierley and Fedorov, 2010) or to a climate state with weak or no zonal

Published by Copernicus Publications on behalf of the European Geosciences Union. 
SST gradient and without ENSO variability (Philander and Fedorov, 2003a; Fedorov et al., 2006). Fedorov et al. (2006) even suggest the "Pliocene Paradox": the tropical climate states, in both Pliocene and today, are quite different, but subject to about the same forcing. In their view, this "permanent" El Niño-like state could be a major factor to explain the warmth of the early mid-Pliocene.

Coupled climate model simulations, however, have not (yet) found a "permanent" El Niño-like state for the Pliocene. Haywood et al. (2007) examine the thermal structure of tropical oceans and, in particular, zonal temperature gradients in the Pacific using the HadCM3 model. They carried out five model simulations: one pre-industrial run, a Pliocene simulation and three sensitivity experiments in which the zonal SST gradients across the different ocean basins are varied. Consistent with proxy data, increased SSTs in the eastern equatorial Pacific are found, however, even with a significantly reduced east-west temperature gradient $\left(1.92^{\circ} \mathrm{C}\right.$ on average) as compared to today, the model shows clear ENSO variability. These simulations do not support the existence of "permanent" El Niño-like conditions in the Pliocene. Furthermore, their sensitivity runs indicate that it is unlikely that permanent El Niño-like conditions, even if they existed, caused the warmth of the mid-Pliocene. Similar results have been found by Bonham et al. (2009), who showed in several Pliocene model experiments, that regional patterns of precipitation and surface temperature changes associated with present-day El Niño teleconnections can be reproduced without the existence of a permanent El Niño, or without any eastern Pacific SST warming at all. Jochum et al. (2009) tested the hypothesis that the emergence of the Halmahera island in the Pliocene could have changed the Indonesian throughflow in such a way that the zonal SST gradient in the tropical Pacific would be reduced. They used a coupled climate model with different configurations of the Indonesian islands and their simulations show interannual ENSO variability with a slightly shifted west Pacific warm pool. These results, nevertheless, do not exclude the possibility of the existence of a "permanent" El Niño state, however, model simulations of even warmer periods in Earth history also suggest ongoing ENSO variability (Huber and Caballero, 2003; Galeotti et al., 2010). Also, recent proxy data, that resolve interannual variability, indicate persisting El Niño variability in the Pliocene (Watanabe et al., 2011; Scroxton et al., 2011).

In this paper, the problem of the Pliocene climatology and El Niño variability is approached from a dynamical systems point of view. Within this view, ENSO arises because the Pacific climatology is susceptible to an oscillatory instability. The propagation features of the pattern which is amplified (usually referred to as the ENSO mode) can be described by a delayed-oscillator mechanism (e.g., the recharge/discharge mechanism, Jin, 1997). The amplitude of the spatial pattern of the mode is determined by the distance to criticality and external noise according to what is called a stochastic Hopf bifurcation
(Neelin and Dijkstra, 1995; Frankcombe et al., 2009).

Within this framework, a "permanent" El Niño state would refer to a climatology with a small zonal temperature gradient which would be so stable that noise would not be able to excite any El Niño variability. Such states have indeed been found in early so-called flux-corrected coupled models (Neelin and Dijkstra, 1995), but they were shown to be an artifact of the flux-correction procedure. As soon as both the climatology and El Niño are dependent on coupled feedbacks (Dijkstra and Neelin, 1995), such "permanent" El Niño states disappear and simultaneously it is difficult to eliminate the Hopf bifurcation associated with the El Niño variability. On the other hand, under certain boundary conditions, it may be possible to create climatological mean states with a reduced zonal SST gradient, that still show interannual variability.

In the following, we address the dynamics of the tropical Pacific climatology and ENSO in the Pliocene using a fullycoupled intermediate complexity model (Neelin and Dijkstra, 1995; van der Vaart et al., 2000). To be self-contained, a brief description of the model components is given in Sect. 2, together with the adaptation of the model to Pliocene climate conditions. Section 3 contains the main results, where we look at changes in the equator-to-pole temperature gradient, increased greenhouse gas concentrations and the presence of an open Panama gateway on the Pacific climate and ENSO variability. In the final Sect. 4, we compare our findings with proxy data compiled by the Pliocene Research, Interpretation and Synoptic Mapping group (PRISM, Dowsett and Robinson, 2009) and discuss and summarize our results.

\section{Model description}

The model used for this study (van der Vaart et al., 2000) is a fully coupled variant of the Zebiak-Cane model (Zebiak and Cane, 1987). It captures the evolution of large-scale motions in the tropical ocean and atmosphere in an idealized Pacific domain. In contrast to the Zebiak-Cane model, the present model is not an anomaly model around a prescribed climatological mean state, but the model itself generates the mean climate state and its variability. This model has been described, in detail, in Dijkstra and Neelin (1995); van der Vaart et al. (2000).

\subsection{The coupled ocean-atmosphere model}

The ocean component of the model consists of a shallowwater layer of mean depth $H$ with an embedded mixed layer of fixed depth $H_{1}$ (see Fig. 1). The ocean basin has a zonal extension $L$ and is unbounded in the meridional direction. The flow evolution in the shallow-water layer with velocity field $(u, v, w)$ and thermocline displacement $h$ (from its equilibrium depth $H$ ) is described by a reduced-gravity model, where the active layer has a density $\rho$ and the motionless 
layer below a density $\rho+\Delta \rho$. The equations are (Zebiak and Cane, 1987):

$$
\frac{\partial u}{\partial t}+a_{\mathrm{m}} u-\beta_{0} y v+g^{\prime} \frac{\partial h}{\partial x}=\frac{\tau^{x}}{\rho H},
$$

$\beta_{0} y u+g^{\prime} \frac{\partial h}{\partial y}=\frac{\tau^{y}}{\rho H}$,

$\frac{\partial h}{\partial t}+a_{\mathrm{m}} h+c_{\mathrm{o}}^{2}\left(\frac{\partial u}{\partial x}+\frac{\partial v}{\partial y}\right)=0$,

with boundary conditions

$\int_{-\infty}^{\infty} u(0, y, t) d y=0, u(L, y, t)=0$.

The equations for the surface (Ekman) layer velocities $\left(u_{\mathrm{s}}, v_{\mathrm{s}}\right)$ are

$a_{\mathrm{s}} u_{\mathrm{s}}-\beta_{0} y v_{\mathrm{s}}=\frac{H_{2}}{H} \frac{\tau^{x}}{\rho H_{1}}$,

$a_{\mathrm{s}} v_{\mathrm{s}}-\beta_{0} y u_{\mathrm{s}}=\frac{H_{2}}{H} \frac{\tau^{y}}{\rho H_{1}}$.

where $H_{2}=H-H_{1}$. In the equations above, $a_{\mathrm{m}}$ and $a_{\mathrm{s}}$ are linear damping coefficients, in the shallow water and Ekman layer, respectively. $\boldsymbol{\tau}=\left(\tau^{x}, \tau^{x}\right)$ is the wind stress vector, $g^{\prime}=g \Delta \rho / \rho$ is the reduced gravity and $c_{\mathrm{O}}=\sqrt{g^{\prime} H}$ is the phase speed of the first oceanic baroclinic Kelvin mode.

The zonal wind stress $\tau^{x}$ is decomposed into an external and a coupled contribution:

$\tau^{x}=\tau_{\mathrm{ext}}^{x}+\tau_{\mathrm{c}}^{x}$,

The coupled part of the wind stress is assumed to be proportional to the zonal windfield $u_{\mathrm{a}}$, i.e., $\tau_{\mathrm{c}}^{x}=\gamma_{\tau} u_{\mathrm{a}}$, with $\gamma_{\tau}$ a constant. The external wind stress $\tau_{\mathrm{ext}}^{x}$ is the part of the wind stress that does not depend on the coupled feedbacks within the basin and can be interpreted as the easterly wind stress component due to the Hadley circulation (Dijkstra and Neelin, 1995) and, hence, directly coupled to the equator-topole gradient. It is assumed constant in the zonal direction and in the meridional direction the external wind stress is assumed to be symmetric with respect to the equator, having the form (van der Vaart et al., 2000)

$\tau_{\mathrm{ext}}^{x}=-\tau_{0} e^{\left[-\frac{\left(y / L_{\mathrm{a}}\right)^{2}}{2}\right]}$,

where $\tau_{0}$ is a typical amplitude of the wind stress $\left(\tau_{0} \sim 0.01 \mathrm{~Pa}\right)$ and $L_{\mathrm{a}}$ the atmospheric Rossby deformation radius. The meridional wind-stress component $\tau^{y}$ is neglected in this model.

The evolution of the sea surface temperature $T$ is described by

$\frac{\partial T}{\partial t}+a_{T}\left(T-T_{0}\right)+\frac{w_{1}}{H_{1}} \mathcal{H}\left(w_{1}\right)\left(T-T_{\mathrm{S}}(h)\right)+u_{1} \frac{\partial T}{\partial x}+v_{1} \frac{\partial T}{\partial y}=0$,

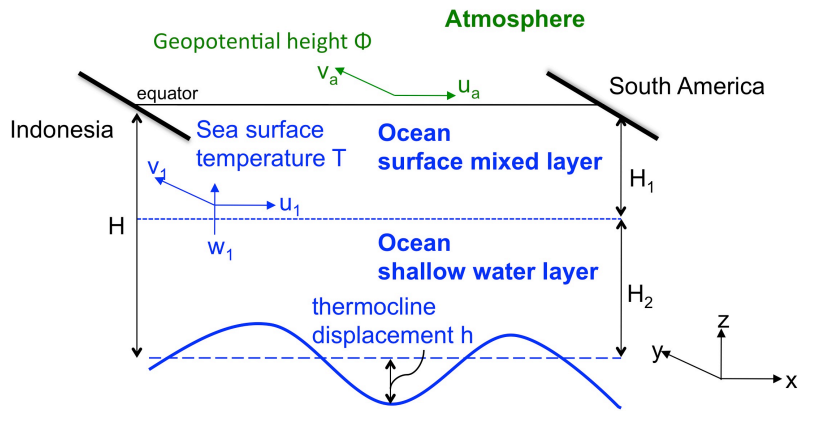

Fig. 1. Schematic representation of the Zebiak-Cane model showing the shallow-water layer with embedded surface mixed layer in the ocean. The shallow-water layer is bounded below by the thermocline. Coupled to the ocean part there is the atmosphere model with horizontal velocities and geopotential height.

where $a_{T}$ is a linear damping coefficient, $u_{1}=u_{\mathrm{s}}+u$ and $v_{1}=v_{\mathrm{s}}+v$ are the horizontal velocities in the mixed layer, $w_{1}=w_{\mathrm{s}}+w$ the vertical velocity just below the mixed layer, $\mathcal{H}$ the Heaviside function and $T_{0}$ is the radiation equilibrium temperature. The subsurface temperature $T_{\mathrm{S}}$ depends on the vertical temperature distribution and, hence, on the thermocline depth $h$ according to

$T_{\mathrm{s}}(h)=T_{\mathrm{s} 0}+\left(T_{0}-T_{\mathrm{s} 0}\right) \tanh \left(\frac{h+h_{0}}{\hat{H}}\right)$,

where $\hat{H}$ and $h_{0}$ represent control parameters for the steepness and the offset of $T_{\mathrm{s}}$ profile, and $T_{\mathrm{s} 0}$ is a characteristic temperature of the water being upwelled into the mixed layer.

The ocean model is coupled to a Gill atmosphere model (Gill, 1980) with zonal and meridional velocities $\left(u_{\mathrm{a}}, v_{\mathrm{a}}\right)$, geopotential height $\phi$ and a linear damping coefficient $A$. The atmosphere is driven by heat fluxes from the ocean that depend linearly on the anomalies of sea surface temperature $T$ with respect to the radiation equilibrium temperature $T_{0}$, with proportionality constant $\alpha_{T}$. The governing equations of the atmosphere model are

$$
\begin{aligned}
& \frac{\partial u_{\mathrm{a}}}{\partial t}+A u_{\mathrm{a}}-\beta_{0} y v_{\mathrm{a}}-\frac{\partial \phi}{\partial x}=0, \\
& \frac{\partial v_{\mathrm{a}}}{\partial t}+A v_{\mathrm{a}}+\beta_{0} y u_{\mathrm{a}}-\frac{\partial \phi}{\partial y}=0, \\
& \frac{\partial \phi}{\partial t}+A \phi-c_{\mathrm{a}}^{2}\left(\frac{\partial u_{\mathrm{a}}}{\partial x}+\frac{\partial v_{\mathrm{a}}}{\partial y}\right)=\alpha_{T}\left(T-T_{0}\right),
\end{aligned}
$$

where $c_{\mathrm{a}}$ is the phase speed of the atmospheric Kelvin wave.

\subsection{Control simulation: standard case}

In order to obtain the proper climatology of the present-day Pacific together with realistic ENSO variability, a control case is defined, where the standard parameter values, as in Table 1, are used. Results of a 20 year simulation under these 

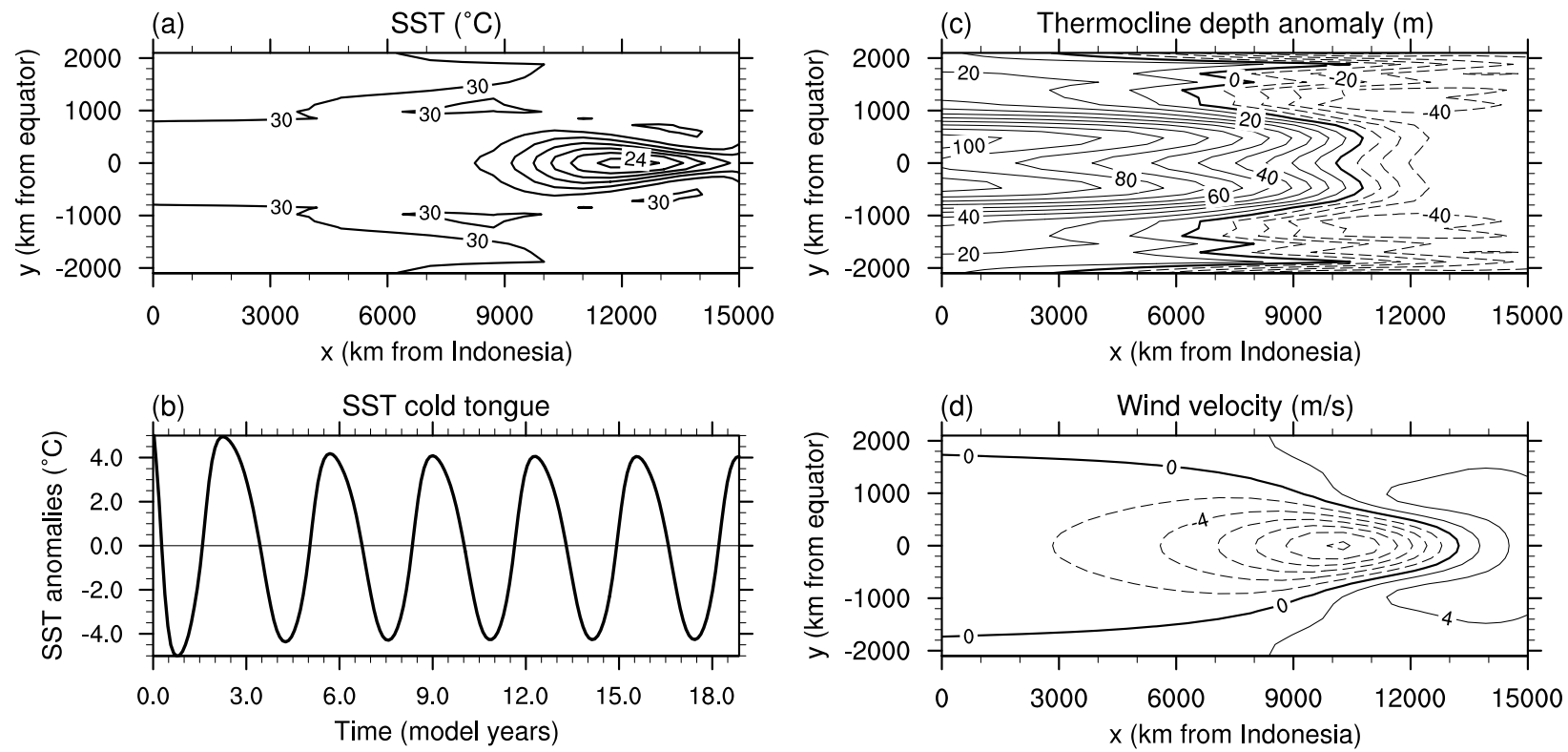

Fig. 2. Climatology and variability as simulated by the model under present-day conditions with standard parameter values, as indicated in Table 1. The radiation equilibrium temperature $T_{0}=30^{\circ} \mathrm{C}$ and the external wind-stress amplitude $\tau_{0}=0.01 \mathrm{~Pa}$. (a) Time-mean spatial SST distribution in ${ }^{\circ} \mathrm{C}$. Contour interval is $1{ }^{\circ} \mathrm{C}$. (b) SST anomalies (in ${ }^{\circ} \mathrm{C}$ ) in the cold tongue on the equator at $x=12500 \mathrm{~km}$ from Indonesia. (c) Time-mean thermocline depth anomaly $h$ (in $\mathrm{m}$ ). Contour interval is $10 \mathrm{~m}$. (d) Time-mean zonal wind velocity $u_{\mathrm{a}}$ (in $\mathrm{m} \mathrm{s}^{-1}$ ). Contour interval is $2 \mathrm{~m} \mathrm{~s}^{-1}$.

parameters are shown in Fig. 2. A contour plot of the time mean sea surface temperature $T$ (Fig. 2a) indicates that the cold tongue with a minimal temperature of about $24^{\circ} \mathrm{C}$ is situated at a realistic position in the east (about $12000 \mathrm{~km}$ from Indonesia, or at $x=0.8 L$ ). The position of the SST minimum and the increasing SST towards the coast of South America is determined by the coupled feedbacks within the basin, i.e., the upwelling and thermocline feedback as explained in Dijkstra and Neelin (1995). A warm pool is observed in the western part of the basin, having the radiative equilibrium temperature $T_{0}=30^{\circ} \mathrm{C}$. Periodic variations of SST anomalies (with respect to the mean state in Fig. 2a) in the cold tongue (at $x=0.8 L$ ) are found (Fig. 2b) with an amplitude of $\sim 4{ }^{\circ} \mathrm{C}$ and a period of $\sim 3.5 \mathrm{yr}$. The timemean thermocline depth $h$ is shallow in the eastern part of the basin and deep in the west (Fig. 2c) with the typical slope in the thermocline across the basin. The time-mean zonal wind response $u_{\mathrm{a}}$ (Fig. 2d) shows the intensification of the easterly winds over the whole central equatorial Pacific with a maximum to the west of the cold tongue.

In summary, this control case shows that under the chosen standard set of parameters the basic features of the presentday Pacific climatology and ENSO variability are well captured by the model. Similar results have been obtained by van der Vaart et al. (2000), where also the spatial patterns of thermocline and SST anomalies of ENSO events were presented (not shown here).
Table 1. Standard values of parameters used in the model as in (van der Vaart et al., 2000).

\begin{tabular}{l|l}
\hline$L=1.5 \times 10^{7} \mathrm{~m}$ & $c_{0}=2 \mathrm{~m} \mathrm{~s}^{-1}$ \\
$c_{a}=30 \mathrm{~m} \mathrm{~s}^{-1}$ & $H=200 \mathrm{~m}$ \\
$H_{1}=50 \mathrm{~m}$ & \\
$F_{0}=\frac{\tau_{0} L}{c_{0}^{2} \rho H}=0.2$ & $\delta_{s}=0.3$ \\
$r=\frac{a_{m} L}{c_{0}}=0.1$ & $\eta_{1}=\frac{h}{\hat{H}}=5.01$ \\
$\epsilon_{S}=\frac{a_{s} L}{c_{0}}=37.5$ & $\delta=1.0$ \\
$\gamma_{s}=\frac{H_{2}}{H_{1}} F_{0}=3.0$ & $\alpha=\frac{L_{y}}{L_{\mathrm{a}}}=0.2$ \\
$\Lambda_{s}=\frac{L_{y}}{L}$ & $\Lambda_{s}=\frac{L_{y}}{L}=2.0 \times 10^{-2}$ \\
$\epsilon_{a}=\frac{\mathrm{AL}}{c_{0}}=1.25$ & $\alpha_{w}=\frac{H_{1}}{\tilde{H}}=1.0$ \\
$\mu=\frac{\alpha_{T} \Delta T L}{c_{a}^{3}}=3.0$ & $\eta_{2}=\frac{h_{0}}{\hat{H}}=0.5$ \\
$\epsilon_{T}=\frac{a_{T} L}{c_{0}}=0.694$ & $T_{0}=30$ \\
$\delta_{w}=5.0 \times 10^{-2}$ & $T_{s 0}=23.0$ \\
\hline
\end{tabular}

\subsection{Pliocene conditions}

We mimic the changes in radiative forcing between Pliocene and present day through a change in the radiation equilibrium temperature $T_{0}$. This is the temperature which would occur in the absence of ocean dynamics, i.e., through a local surface 
heat flux equilibrium over the ocean. As mentioned above, the early mid-Pliocene warm period was characterised by global mean surface temperatures approximately $3{ }^{\circ} \mathrm{C}$ higher than today (Dowsett and Robinson, 2009). Although the dynamics involving $T_{0}$ are complicated and beyond the scope of this paper, a higher global mean temperature implies also a higher $T_{0}$. This motivates us to study the sensitivity of the climate states and the ENSO variability of the model versus $T_{0}$.

Within the theory on the Pacific cold tongue (Dijkstra and Neelin, 1995), an initially weak east-west SST gradient due to the external wind stress is amplified by coupled feedbacks leading to the present-day cold tongue position and amplitude. Several studies have suggested that the Pliocene Hadley circulation was weaker due to the smaller equator-to-pole temperature gradient (Tziperman and Farrell, 2009; Brierley et al., 2009; Etourneau et al., 2010). Furthermore, in a warmer climate the atmosphere contains more water, while precipitation is constrained by the radiation budget. Consequently, the atmospheric overturning circulation becomes weaker in a warmer climate (Held and Soden, 2006; Vecchi and Soden, 2007). Therefore, a sensitivity study will be performed as well of the effect of an increasing/decreasing amplitude of the external wind stress $\tau_{0}$ (in Eq. 5) on the Pacific climate state and ENSO characteristics in the model.

Finally, the Pliocene continental configuration was slightly different from the modern one in that the Central American Seaway was still open. This gateway connecting the tropical Atlantic and Pacific Oceans was located at about $3^{\circ} \mathrm{N}$. Reconstructions of the upper-water column hydrography of the eastern and western equatorial Pacific using $\delta^{18} \mathrm{O}$ and $\delta^{13} \mathrm{C}$ proxy records have indicated that surface waters of the eastern equatorial Pacific were warmer than those in the west between 5 and $4 \mathrm{Ma}$ (Cannariato and Ravelo, 1997). This can be explained by warm Atlantic surface water flowing through the (still open) Central American seaway into the Pacific and increasing the local sea surface temperatures. To model this effect, we assume that these warm waters affect the surface layer of the eastern Pacific ocean only. Hence, in the model SST equation, we add a local relaxation term proportional to the difference between the eastern equatorial Pacific SST and western equatorial Atlantic temperature $T_{\mathrm{A}}$. The modified SST Eq. (6) then becomes:

$$
\begin{aligned}
& \frac{\partial T}{\partial t}+a_{T}\left(T-T_{0}\right)+\frac{w_{1}}{\tilde{H}} \mathcal{H}\left(w_{1}\right)\left(T-T_{\mathrm{S}}(h)\right)+ \\
& u_{1} \frac{\partial T}{\partial x}+v_{1} \frac{\partial T}{\partial y}+a_{T} f(x, y)\left(T-T_{\mathrm{A}}\right)=0,
\end{aligned}
$$

with

$f(x, y)=e^{\frac{x-L}{L_{\mathrm{PG}}}} \cdot e^{-\frac{4}{W_{\mathrm{PG}}^{2}}\left(y-Y_{\mathrm{PG}}\right)^{2}}$.

The function $f(x, y)$, with zonal and meridional length scales $L_{\mathrm{PG}}$ and $W_{\mathrm{PG}}$ controls how far the effect of warm Atlantic water extends into the Pacific and the parameter $Y_{\mathrm{PG}}$ determines the latitudinal position of the gateway.

\section{Results}

In the first subsection we study the changes in the Pacific climatology and ENSO variability to variations of the radiation equilibrium temperature $T_{0}$ and the external wind stress strength $\tau_{0}$. In the second subsection, we consider the effect of an open Central American Gateway.

\subsection{Sensitivity to the external wind stress and the radiation equilibrium temperature}

We perform a suite of model experiments where two parameters, the amplitude of the external wind stress and the radiation equilibrium temperature are changed. Each simulation is integrated for about $20 \mathrm{yr}$ and the last $14 \mathrm{yr}$ of output are used for analysis. As the model solutions are quickly in equilibrium, such a short integration time is sufficient to determine ENSO period and time-mean state properties. One of the most important variables for the background climate state is the position of the cold tongue, which we define as the zonal location along the equator where the (time-averaged) SST is minimal.

The amplitude of the external wind stress is varied within a range $\tau_{0}=[0.005-0.02] \mathrm{Pa}$, while the standard value in the control simulation is $\tau_{0}=0.01 \mathrm{~Pa}$. Simulations were done for each value of $\tau_{0}$ with increments of $0.001 \mathrm{~Pa}$. The timemean SST distributions along the equator in Fig. 3a show that the zonal location of the cold tongue $x_{\mathrm{C}}$ shifts to the east with increasing external wind stress. The cold tongue is located approximately $11000 \mathrm{~km}$ from Indonesia for small $\tau_{0}$ and shifts eastward by about $2000 \mathrm{~km}$ for large $\tau_{0}$.

The radiation equilibrium temperature is varied between $T_{0}=[28-32]^{\circ} \mathrm{C}$ with increments of $0.5^{\circ} \mathrm{C}$. For the standard value of $\tau_{0}=0.01 \mathrm{~Pa}$ the position of the cold tongue shifts westward with increasing $T_{0}$ (Fig. 3d). Figure 4a shows the zonal position of the cold tongue as a function of the external wind stress and the radiation equilibrium temperature. The eastward shift with increasing $\tau_{0}$ occurs for all values of $T_{0}$ considered, as well as the westward shift with increasing $T_{0}$ occurs for all values of $\tau_{0}$. For $\tau_{0}=0.01 \mathrm{~Pa}, x_{\mathrm{C}}$ shifts from approximately $12750 \mathrm{~km}$ from Indonesia for small $T_{0}$ to about $11500 \mathrm{~km}$ from Indonesia for higher $T_{0}$. The westward shift of the cold tongue due to increasing $T_{0}$ is more pronounced for small external wind stress.

Due to coupled feedbacks, the sensitivity of SST in the eastern Pacific (Fig. 4a) to external wind stress changes is large. This effect is related to the thermocline feedback causing more cold waters being upwelled into the surface layer with increasing wind stress and, as a result, the eastern equatorial Pacific SST decreases. Figure $4 b$ shows the temperature of the cold tongue for all applied values of $\tau_{0}$ and $T_{0}$. At the standard radiation equilibrium temperature of $T_{0}=30^{\circ} \mathrm{C}$, a $\tau_{0}=0.01 \mathrm{~Pa}$ produces a minimum SST of $T \approx 23.5^{\circ} \mathrm{C}$ which decreases to $\approx 20.5^{\circ} \mathrm{C}$ for the largest applied $\tau_{0}$. A similar decrease in the cold-tongue temperature 

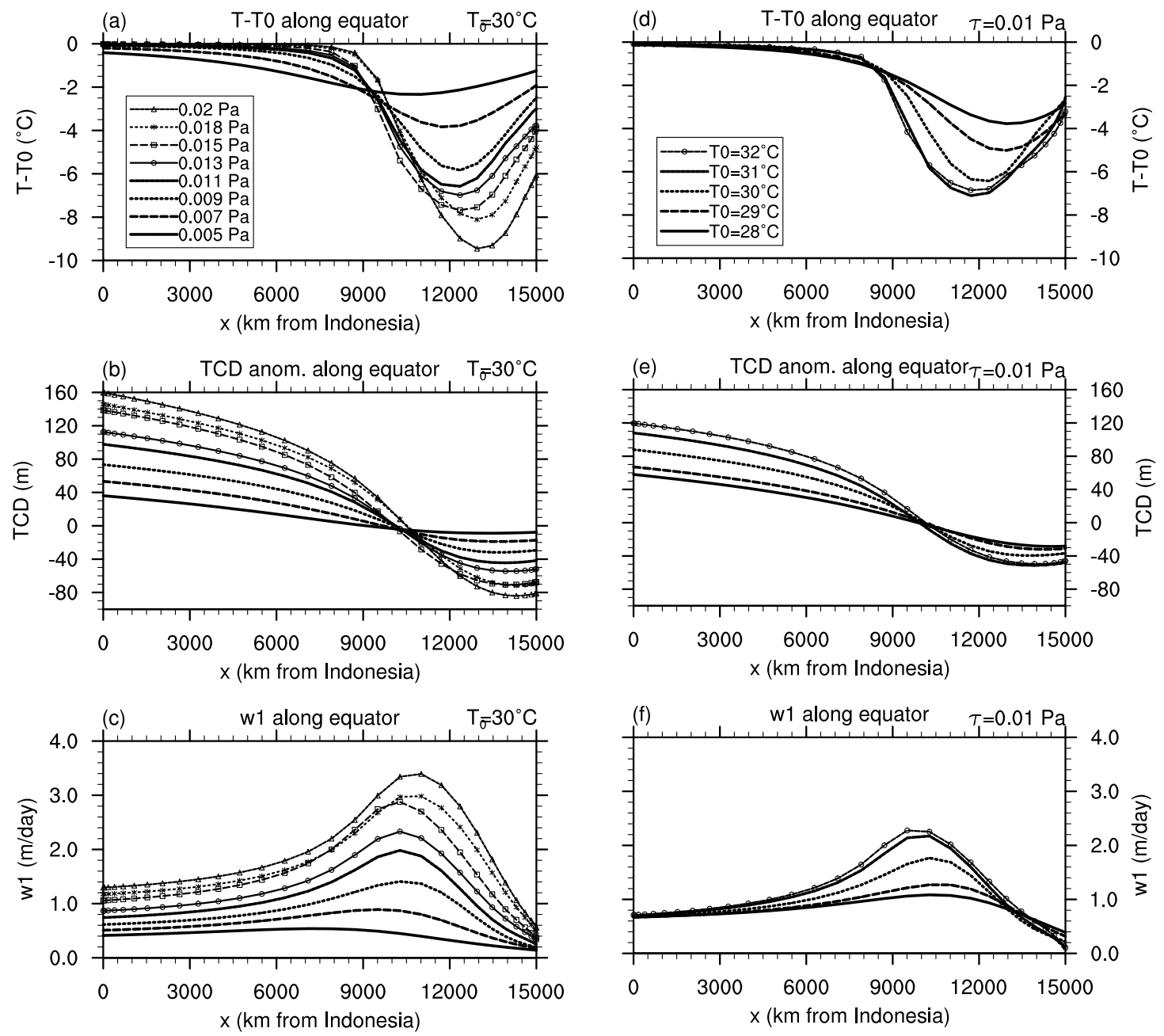

Fig. 3. Effects of changing the external wind stress $\tau_{0}$ and the radiation equilibrium temperature $T_{0}$ on the climatology (i.e., the time-mean) of the tropical Pacific. (a-c) Zonal SST distribution (a), thermocline depth anomaly (b) and upwelling velocity below the mixed layer $w_{1}$ (c) along the equator for different $\tau_{0}$ between $0.005-0.02 \mathrm{~Pa}$. The equilibrium temperature $T_{0}$ is kept constant at $T_{0}=30^{\circ} \mathrm{C}$. The legend in (a) holds for $(\mathbf{a}-\mathbf{c})$. (d-f) Zonal SST distribution (d), thermocline depth anomaly (e) and upwelling velocity below the mixed layer $w_{1}(\mathbf{f})$ along the equator for different $T_{0}$ between $28-32{ }^{\circ} \mathrm{C}$. The external wind stress amplitude $\tau_{0}$ is kept constant at $\tau_{0}=0.01 \mathrm{~Pa}$. The legend in (d) holds for (d-f).

with increasing $\tau_{0}$ is simulated for all other values of $T_{0}$. As the sensitivity in the western Pacific is much smaller, the zonal SST gradient increases with $\tau_{0}$. This is shown in Fig. $4 \mathrm{c}$ where the zonal SST difference $T_{\mathrm{E}}-T_{\mathrm{W}}$ versus $\tau_{0}$ and $T_{0}$ is plotted. For example, for $T_{0}=30^{\circ} \mathrm{C}$, the zonal SST difference increases from $1^{\circ} \mathrm{C}$ at $\tau_{0}=0.005 \mathrm{~Pa}$ to $7^{\circ} \mathrm{C}$ at $\tau_{0}=0.02 \mathrm{~Pa}$.

Although the changes in mean SST under varying $T_{0}$ and $\tau_{0}$ are larger in the east than in the west, the sensitivity of the mean thermocline to $T_{0}$ and $\tau_{0}$ is weaker in the eastern Pacific than in the western Pacific (Fig. 3b, e) as has been observed in other models as well (DiNezio et al., 2009). The resulting large changes in the eastern tropical Pacific SST are due to strongly increased upwelling velocities for strong wind $\tau_{0}$ and warmer radiation equilibrium temperatures $T_{0}$
(Fig. 3c, f). The maximum value of the upwelling velocity below the mixed layer $w_{1}$ along the equator shifts westward with decreasing $\tau_{0}$ and increasing $T_{0}$, which explains the shift of the minimum SST.

The temperature and position of the cold tongue changes quite dramatically when increasing $\tau_{0}$ above 0.008 at $T_{0}=30^{\circ} \mathrm{C}$ (Fig. $\left.4 \mathrm{a}-\mathrm{b}\right)$. This is related to changes that occur in ENSO variability: when the external wind stress $\tau_{0}$ is small, the system has a weak cold tongue state with high SSTs and there is no ENSO variability. Once $\tau_{0}$ reaches a critical value (at the first Hopf bifurcation), this steady state becomes unstable, leading to the generation of oscillatory ENSO behaviour and a change in the background state. In Fig. 3b-d, the transition between the two regimes is indicated by the red line. 

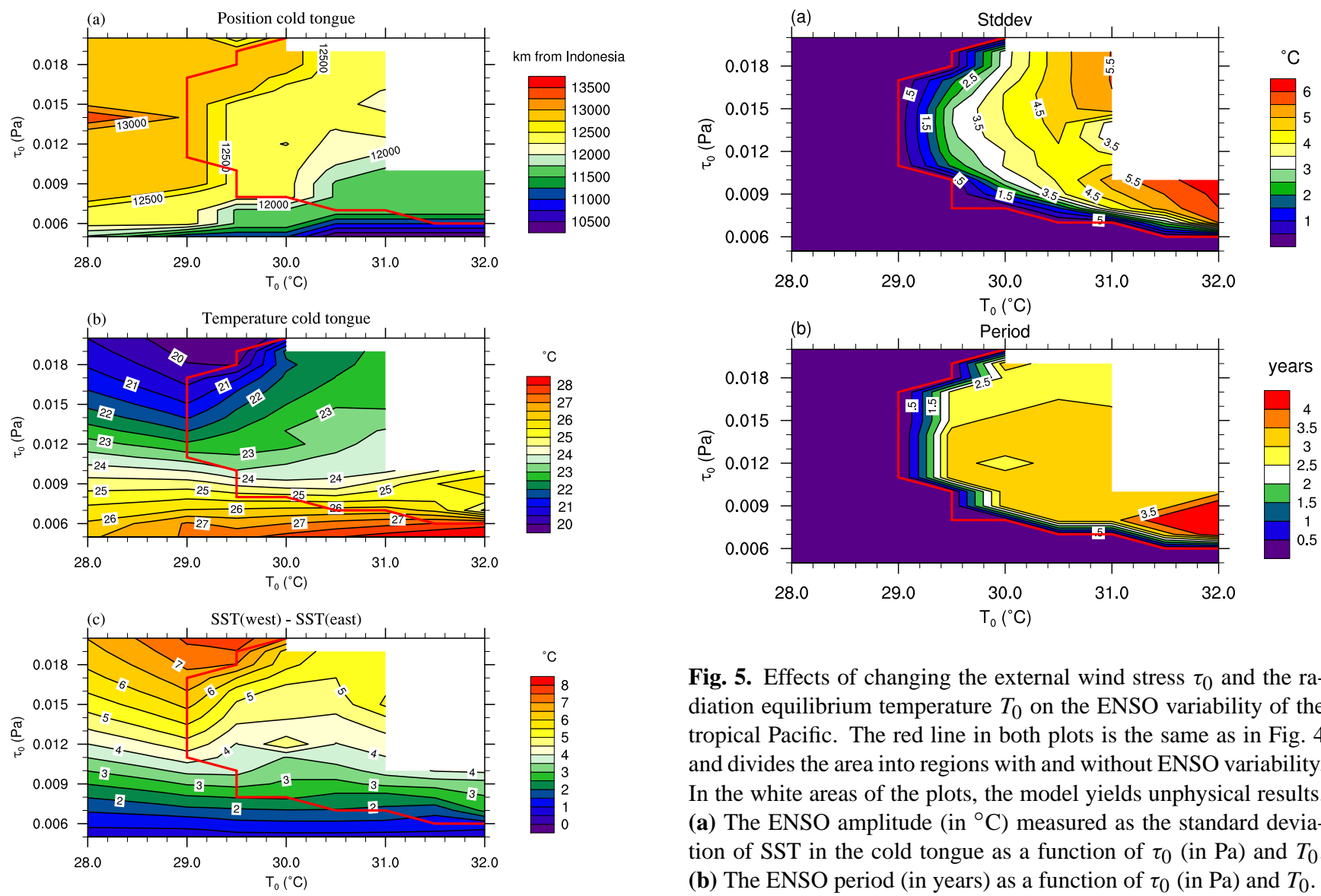

Fig. 4. Effects of changing the external wind stress $\tau_{0}$ and the radiation equilibrium temperature $T_{0}$ on the climatology (i.e., the timemean) of the tropical Pacific. (a) Time-mean zonal position of the cold tongue (in $\mathrm{km}$ from Indonesia) at the equator as a function of $\tau_{0}$ and $T_{0}$. (b) Time-mean temperature of the cold tongue as a function of $\tau_{0}$ and $T_{0}$. (c) Time-mean zonal SST difference between west and east Pacific at the equator as a function of $\tau_{0}$ and $T_{0}$. The red line in the contour plots divides the area into regions with and without ENSO variability. Left of the red line there is no ENSO variability. White area: the model yields unphysical results.

In general, the zonal position of the cold tongue $x_{\mathrm{C}}$ and the east-west temperature difference $T_{\mathrm{E}}-T_{\mathrm{W}}$ depends more strongly on variations in the external wind stress $\tau_{0}$ than on the radiation equilibrium temperature $T_{0}$. However, increasing $\tau_{0}$ and increasing $T_{0}$ have counteracting effects on the zonal location of the cold tongue.

The amplitude and period of ENSO variability is shown in Fig. 5. The amplitude is defined as the standard deviation of SST in the cold tongue (i.e., where the minimum SST along the equator occurs) and the period is determined from a spectral analysis of the SST time series in the cold tongue. For equilibrium temperatures $T_{0}$ up to $28-29^{\circ} \mathrm{C}$, the ENSO mode is dampened for all $\tau_{0}$ because the coupled feedbacks involved in the system are not strong enough to sustain oscil-

latory behaviour. For temperatures $T_{0}=29.5-32{ }^{\circ} \mathrm{C}$, a sufficiently large $\tau_{0}$ is needed $\left(\tau_{0} \approx 0.009 \mathrm{~Pa}\right.$ for $T_{0}=30^{\circ} \mathrm{C}$ ) to generate ENSO variability. Both amplitude and period quickly increase to values of $\sim 3^{\circ} \mathrm{C}$ and $\sim 3.5 \mathrm{yr}$, respectively, for $\tau_{0}=0.01 \mathrm{~Pa}$ and $T_{0}=30^{\circ} \mathrm{C}$. For $T_{0}=29.5^{\circ} \mathrm{C}$ ENSO behaviour is absent for very large values of $\tau_{0}$, since then the mean state (which also changes with $\tau_{0}$ ) is stable again. For the range $T_{0}=31-32{ }^{\circ} \mathrm{C}$, the critical value of $\tau_{0}$ (first Hopf bifurcation) decreases to $\tau_{0} \sim 0.006 \mathrm{~Pa}$, and ENSO variability is much stronger with amplitudes reaching $6^{\circ} \mathrm{C}$ and periods between 3.5 and $4.5 \mathrm{yr}$ (Fig. 5). A similar behaviour is found by Jin (1998) who investigated the dependence of the amplitude and period of the ENSO mode on the dynamical coupling strength. In our case, when $\tau_{0}$ is too small, the system has a weak cold tongue state, which is not enough to sustain an oscillatory ENSO mode because the thermocline feedback is weak (Jin, 1998). When $\tau_{0}$ is very large, the Eastern Pacific becomes very cold and this probably gives rise to a weak stratification that leads to reduced feedbacks and consequently to a dampened ENSO mode. In the range of $\tau_{0}$ and $T_{0}$, where ENSO variability exists, decreasing wind strength, in general, leads to a smaller ENSO amplitude because of the weakened thermocline tilt in the mean state (DiNezio et al., 2011). 

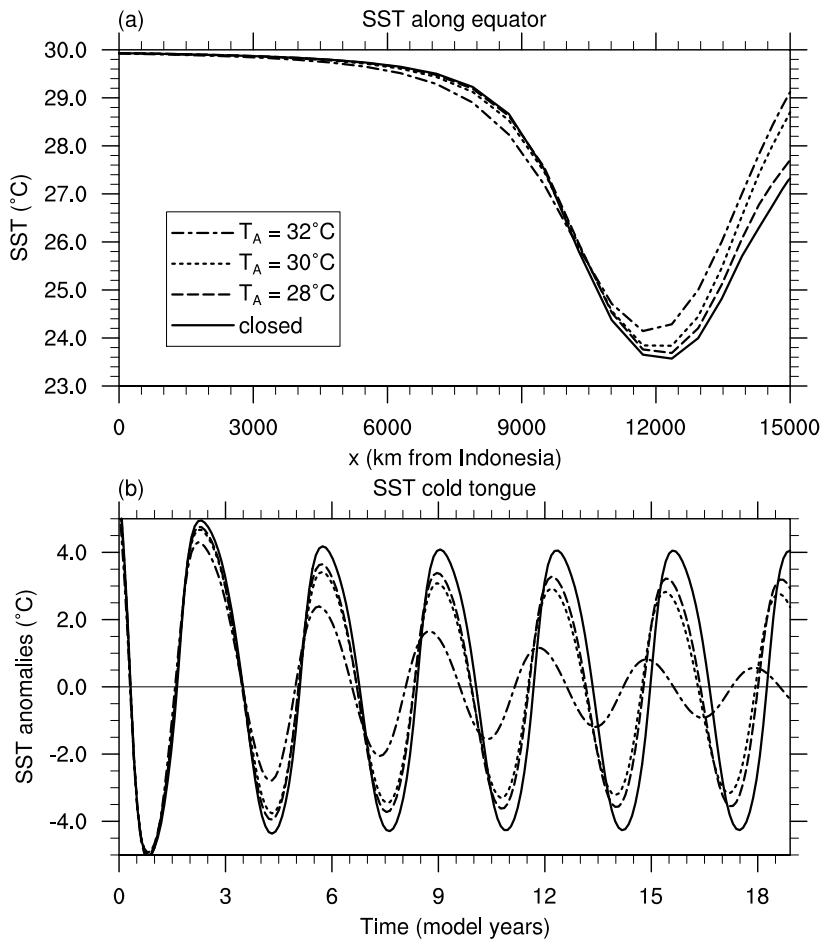

Fig. 6. Effect of an open Panama gateway on the Pacific timemean zonal SST distribution at the equator and the SST variability in the cold tongue. The radiation equilibrium temperature and the external wind stress are fixed at $T_{0}=30^{\circ} \mathrm{C}$ and $\tau_{0}=0.01 \mathrm{~Pa}$, respectively. (a) Time-mean zonal SST distribution at the equator for three different western Atlantic inflow temperatures $T_{\mathrm{A}}$ and the standard case with closed gateway. (b) SST anomalies (in ${ }^{\circ} \mathrm{C}$ ) in the cold tongue (minimum SST along the equator) for three different western Atlantic inflow temperatures $T_{\mathrm{A}}$ and the standard case with closed gateway.

\subsection{Effect of Panama gateway}

To represent the effect of the Panama gateway, we use the modified SST Eq. (9). To obtain the magnitude of the length $L_{\mathrm{PG}}$, a scale analysis is performed where we assume that the advection term in the zonal direction $u_{1} \frac{\partial T}{\partial x}$ (representing the Atlantic inflow with a characteristic zonal velocity $U$ ) is of the same order as the term $a_{T} f(x, y)\left(T-T_{\mathrm{A}}\right)$. Hence, $U \frac{T-T_{\mathrm{A}}}{L_{\mathrm{PG}}} \sim a_{T}\left(T-T_{\mathrm{A}}\right)$. From this it follows that $L_{\mathrm{PG}} \sim \frac{U}{a_{T}}$. The flow velocity through the gateway $U$ is of the order $10^{-1} \mathrm{~m} \mathrm{~s}^{-1}$ (von der Heydt and Dijkstra, 2006; Lunt et al., 2008). With a physical damping time scale of SST anomalies $a_{T}=0.925 \times 10^{-7} \mathrm{~s}^{-1}$ (see Table 1), we estimate that the length scale $L_{\mathrm{PG}} \sim 10^{3} \mathrm{~km}$. The PRISM3D continental configuration data (Dowsett and Robinson, 2009) are used to approximate the width $W_{\mathrm{PG}}$ of the throughflow, assuming that this is of the same order as the width of the gateway: we use $W_{\mathrm{PG}} \sim 2.4^{\circ} \simeq 270 \mathrm{~km}$. In the results below, we, therefore, use the parameters $L / L_{\mathrm{PG}}=15$ and $4\left(L_{y} / W_{\mathrm{PG}}\right)^{2}=4.8$ in the function $f(x, y)$ in the modified SST equation (Eq. 9).
First, we consider the case that the gateway opening is located at the equator and the sensitivity of the model climate and ENSO variability to the western Atlantic ocean temperature $T_{\mathrm{A}}$ is explored. Figure $6 \mathrm{a}$ shows the influence of the western equatorial Atlantic ocean $T_{\mathrm{A}}$ on the time-mean SST of the equatorial Pacific ocean. For comparison, the standard case, in which the gateway is closed, is included in the plots. Significant differences in both the SST of the eastern Pacific ocean and the location of the cold tongue are found depending on $T_{\mathrm{A}}$. Opening the gateway leads to an increase of the SST of the eastern equatorial Pacific and this effect becomes stronger if the Atlantic temperature $T_{\mathrm{A}}$ is higher. Furthermore, we find a small westward shift of the position of the cold tongue, which is at most $500 \mathrm{~km}$ for $T_{\mathrm{A}}=32^{\circ} \mathrm{C}$, as if the cold tongue is "pushed away" in the western direction upon opening the gateway. Figure $6 \mathrm{~b}$ shows the effect of the inflowing Atlantic water on the characteristics of the ENSO variability for different temperatures $T_{\mathrm{A}}$. In the presence of warm Atlantic inflow, the amplitude of ENSO amplitude decreases and the variability is dampened in the case of high Atlantic temperature $T_{\mathrm{A}}=32^{\circ} \mathrm{C}$. This may also explain the relatively large shift in the position of the cold tongue when comparing the cases with $T_{\mathrm{A}}=30^{\circ} \mathrm{C}$ and $T_{\mathrm{A}}=32^{\circ} \mathrm{C}$ : When changing from a mean climatology without ENSO variability to one with variability, the mean state changes due to rectification. The period of ENSO variability becomes slightly shorter with increasing inflow temperature.

The throughflow between the equatorial Atlantic and $\mathrm{Pa}$ cific ocean may result in a change of the equilibrium temperature $T_{0}$, which means that besides the direct effect of the throughflow, an additional forcing mechanism is introduced in the system. In other words, we must be careful with comparing the results obtained from these experiments with those of the "gateway-closed" case where this additional forcing is not present. In the appendix, it is shown that the modification of $T_{0}$ by the throughflow is $0.1^{\circ} \mathrm{C}$ at most and can, therefore, be neglected. The insignificance of this term can also be seen from the graphs in Fig. 6, where only the SST of the eastern part of the basin is affected; the SST of the western part stays at the equilibrium temperature $T_{0}$ for all $T_{\mathrm{A}}$.

According to the PRISM3D topography data, the Panama gateway was not exactly located at the equator: it was located at approximately $3^{\circ} \mathrm{N}$, which is equivalent to a distance of $\sim 300 \mathrm{~km}$ from the equator. A latitudinal shift of the gateway is simulated by means of changing the control parameter $Y_{\mathrm{PG}}$. The results of a simulation with $Y_{\mathrm{PG}}=300 \mathrm{~km}$ are shown in Fig. 7 and compared with the control case where the gateway is closed and the case where the gateway is located at the equator. The time-mean SST in the eastern equatorial Pacific ocean hardly changes between the cases with the open gateway at different latitudes (Fig. 7a). The amplitude and period of ENSO variability are smaller than with the gateway closed, but slightly larger than with the gateway at the equator. 

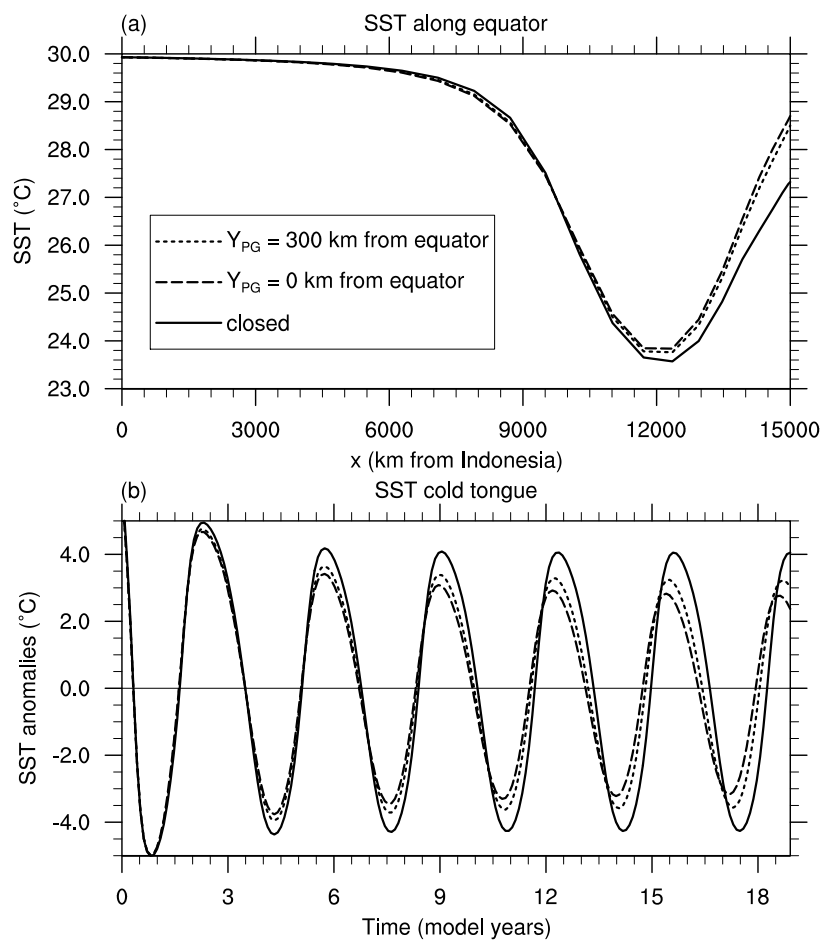

Fig. 7. Effect of the meridional position of the Panama gateway on the Pacific time-mean zonal SST distribution at the equator and the SST variability in the cold tongue. The radiation equilibrium temperature and the external wind stress are fixed at $T_{0}=30^{\circ} \mathrm{C}$ and $\tau_{0}=0.01 \mathrm{~Pa}$, respectively. (a) Time-mean zonal SST distribution at the equator for different positions of the Panaman gateway: $300 \mathrm{~km}$ north of the equator, on the equator and a closed gateway. (b) SST anomalies (in ${ }^{\circ} \mathrm{C}$ ) in the cold tongue (minimum SST along the equator) for different positions of the Panaman gateway: $300 \mathrm{~km}$ north of the equator, on the equator and a closed gateway.

\section{Summary and Discussion}

We have studied the behaviour of ENSO variability and the time-mean tropical Pacific climatology under conditions mimicking the Pliocene climate state within the fully coupled Zebiak-Cane model (van der Vaart et al., 2000). In this model, coupled processes affect both the climatology and the ENSO variability as explained in detail in Dijkstra and Neelin (1995). This is in contrast to the original ZebiakCane model, which had the climatology prescribed. Within our model, the climatology is generated by the coupled processes and, therefore, changes from cases with and without ENSO variability due to rectification.

Both the external wind stress amplitude and the radiation equilibrium temperature have been varied in a range that is potentially important for the early to mid-Pliocene warm period. It has been suggested, that the Hadley circulation was weaker than today in the Pliocene (Brierley et al., 2009; Tziperman and Farrell, 2009; Held and Soden, 2006), which, in our model is represented as a smaller external wind stress $\tau_{0}$. Our simulations show that the zonal position along the equator of the cold tongue $x_{\mathrm{C}}$ shifts to the west with decreasing external wind stress amplitude $\tau_{0}$. Furthermore, the Pliocene was characterised by higher global mean temperatures (Ravelo et al., 2004), which motivates the study of a range of different radiation equilibrium temperatures $T_{0}$ in the model. The $T_{0}$ variation also leads to changes in the zonal position of the cold tongue and we find that it shifts westwards with increasing $T_{0}$ though this effect is smaller than when decreasing the external wind stress $\tau_{0}$. Both effects together may have resulted in a westward shift of the cold tongue of about $1750 \mathrm{~km}$, when assuming the Pliocene radiation equilibrium temperature to be $0.5-1{ }^{\circ} \mathrm{C}$ warmer than the present day climate and about $10 \%$ weaker trade winds $\left(\tau_{0}=0.9, T_{0}=30.5-31{ }^{\circ} \mathrm{C}\right.$ in Fig. $\left.4 \mathrm{a}\right)$

In the Pliocene, the Panama gateway was still open allowing water from the Atlantic to flow into the Pacific (Cannariato and Ravelo, 1997). This has been included in our model by an advection-relaxation balance in the surface temperature. We find that the opening of the gateway induces again a (small) westward shift of the cold tongue and an increase of the SST of the eastern equatorial Pacific.

Hence, all parameters that have been studied in our simulations suggest that in the Pliocene climatology the cold tongue would be shifted to the west as compared to presentday conditions. This is indeed seen in observational data as shown in Fig. 8. In this figure, the annual mean zonal SST distribution along the equator in the Pacific ocean as compiled in the PRISM3D dataset from different proxies (Dowsett and Robinson, 2009) is compared with present day observations averaged from 1971-2000 from two datasets (HadISST Rayner et al., 2003 and NOAA Optimum interpolation Reynolds et al., 2002). The eastern tropical Pacific is much warmer in the Pliocene than in the present day, however, the minimum SST along the equator for the Pliocene is only slightly warmer than the minimum of the present day and its location has shifted about $1100 \mathrm{~km}$ westward. Note, however, that the PRISM data are based only on a few data points along the equator (triangles in Fig. 8), and in particular the minimum SST along the equator is not based on an actual data point. Therefore, the uncertainty in the value of the minimum SST is relatively large. Nevertheless, the minimum SST needs to be somewhere between the data points at $95^{\circ} \mathrm{W}$ and $133^{\circ} \mathrm{W}$ suggesting, in any case, a westward shift of the cold tongue as compared to the HadISST dataset.

In the parameter range of $T_{0}$ and $\tau_{0}$ that we have explored, the model shows climatologies with and without ENSO variability. For example, for very low external wind stress amplitudes at the standard value of the radiation equilibrium temperature, ENSO variability is dampened and the time-mean position of the cold tongue is shifted strongly westwards. In this case, also the temperature of the cold tongue becomes relatively warm while the western equatorial Pacific remains at similar temperatures, thereby, reducing the east-west SST difference along the equator. These climatologies show the 


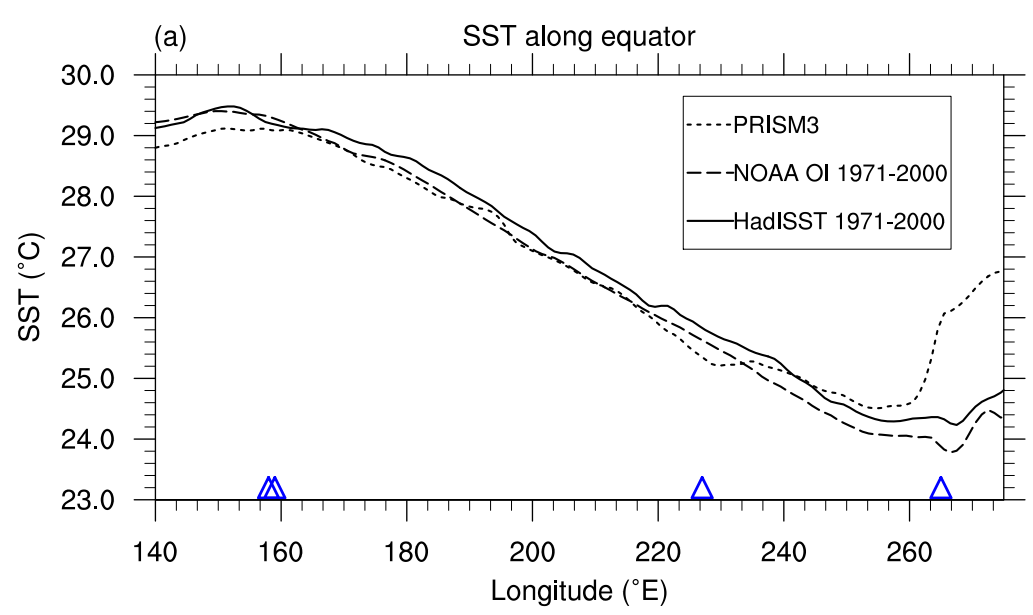

Fig. 8. Zonal SST profile at the equator from observations in different datasets: the HadISST (solid line) and the NOAA Optimum Interpolation SST V2, 1971-2000 timeseries (dashed line) for the present-day conditions. The dotted line denotes the zonal SST profile at the equator as inferred from proxy data for the Pliocene in the PRISM3D dataset. The triangles along the x-axis indicate the zonal position of data points along the equator, where the PRISM data are based on.

largest resemblance with a state that might be called "permanent El Niño", however, note that they occur only for very weak wind stresses. On the other hand, for fixed external wind stress, an increase in the radiation equilibrium temperature leads to a slightly larger east-west SST difference (Fig. 4c) and stronger ENSO variability (Fig. 5).

ENSO variability is present in our model simulations over a large parameter domain. Only for colder than present-day radiation equilibrium temperatures the Pacific climatology is stable (no variability) and together with low values of the external wind stress this leads to a climatology with strongly reduced east-west SST difference. For very high radiation equilibrium temperatures and strong external wind stress, the model results become unphysical (too large amplitude of the thermocline anomaly) and have, therefore, been excluded in the analysis. In the presence of an open Panama gateway, ENSO variability has a smaller amplitude and shorter period as compared to cases without the gateway, however, ENSO variability is damped only if very warm Atlantic water $\left(T_{\mathrm{A}}=32^{\circ} \mathrm{C}\right)$ enters the Pacific at the equator.

Two mechanisms have been proposed that could potentially create 'permanent' El Niño conditions (Chiang, 2009). The first one involves tectonic changes in the region of the Indonesian throughflow. Cane and Molnar (2001) suggested that the northward displacement of the northern tip of New Guinea across the equator at about $5 \mathrm{Ma}$ could have resulted in more warm South Pacific water feeding the equatorial countercurrent and, thereby, warming the west Pacific warm pool which, in turn, allowed the Bjerknes feedback to become active and eventually established the present day strong east-west SST difference.
Testing this hypothesis is beyond the scope of our coupled model, as within this model there is no continental geometry or in- and outflow from other ocean basins. In the case of the Panama gateway, the inflow of warm surface water is relatively straightforward to model by an additional relaxation term, however, in the case of the Indonesian throughflow this method is more difficult to apply mainly because there is outflow through the Indonesian throughflow and the differences, suggested by Cane and Molnar (2001), result from subtle changes of the flow structure north and south of the equator. Fully coupled global climate model simulations have, however, shown that the northward movement of New Guinea would result only in very modest warming of the west Pacific warm pool and the central equatorial Pacific (Jochum et al., 2009). Furthermore, these simulations suggest that a pronounced zonal SST difference and ENSO variability is present with both positions of New Guinea. Therefore, additional modelling work is needed to quantify the effect of a changed Indonesian throughflow on the tropical Pacific climatology.

The second mechanism that has been proposed is of a more global nature and is based on the assumption that the tropical thermocline as a whole was deeper in the Pliocene than today (Philander and Fedorov, 2003b). While deep ocean waters were cooling throughout the last 35 million years, Philander and Fedorov (2003b) suggest that the associated gradual shallowing of the thermocline reached a threshold around 3 million years ago which allowed cool deep waters being upwelled to the surface in the eastern tropical Pacific as well as in other main upwelling regions in the world. Therefore, a substantial east-west temperature gradient along the equator in the Pacific could only develop after about three million years ago. 
While this second mechanism may have contributed to the intensification of the tropical Pacific east-west temperature difference in the Pliocene, our model results indicate that the dynamics of the Pacific climatology and associated variability is more complicated. In the model results, states with and without ENSO variability exist and both in general display a substantial east-west temperature gradient (except the states for very weak external wind stress). Our results further show that the SST difference between two points along the equator is not sufficient to characterise the tropical Pacific climate state, as subtle shifts in the spatial pattern of both the climatology and the variability may occur.

Recently, proxy data have been analysed that have the potential to resolve interannual ENSO variability (Scroxton et al., 2011; Watanabe et al., 2011), and both suggest ongoing interannual variability in the Pliocene tropical Pacific.

In summary, from our model simulations, it seems unlikely that a "permanent" El Niño like Pacific climatology has existed under the Pliocene climate conditions. Coupled feedbacks as, for example, the amplification of the easterly wind due to the existence of a (initially) small eastwest temperature gradient and the subsequently strengthened east-west temperature difference (Bjerknes feedback), make it difficult to establish a climatology with weak zonal temperature gradient and without ENSO variability. This study clearly suggests that Pliocene ENSO variability potentially was similar to today with weaker trade winds and higher global mean temperatures. The position of the cold tongue was most likely shifted westward by $1000-2000 \mathrm{~km}$ with respect to the present day position. Therefore, the east-west SST difference as inferred from proxy records potentially underestimates the real SST gradient.

\section{Appendix A}

\section{Effect of the Atlantic inflow on the equilibrium temperature}

The inflow of Atlantic water through an open Panama Gateway is modelled by adding a term $T-T_{\mathrm{A}}$ to the SST equation (see modified SST Eq. 9). In fact, an extra forcing mechanism is introduced to the system, which may result in a changed equilibrium temperature. In this section, we show that the change in equilibrium temperature due to the throughflow is small and can be neglected.

In the unperturbed case, the equilibrium temperature $\bar{T}$ of the system results from the SST equation (Eq. 6) in steady state and the absence of ocean dynamics (i.e., $u_{1}=v_{1}=$ $\left.w_{1}=0\right)$ and is equal to $T_{0}$. With the additional term in the modified SST equation, the equilibrium temperature becomes:

$a_{T}\left(\left(\bar{T}-T_{0}\right)+f(x, y)\left(\bar{T}-T_{\mathrm{A}}\right)\right)=0$, or

$\bar{T}(x, y)=\frac{T_{0}+T_{\mathrm{A}} f(x, y)}{1+f(x, y)}=T_{0}+\frac{\left(T_{\mathrm{A}}-T_{0}\right) f(x, y)}{1+f(x, y)} \equiv T_{0}+\Delta \bar{T}(\mathrm{~A} 2)$

where $\Delta T(x, y)$ represents the change in the equilibrium temperature $T_{0}$ caused by the Atlantic inflow. To estimate the overall change across the basin, $\Delta \bar{T}(x, y)$ is integrated over the model domain:

$$
\begin{aligned}
& <\Delta \bar{T}>=\left(T_{\mathrm{A}}-T_{0}\right) \frac{L}{L_{y} L} \int_{-\infty}^{\infty} \int_{0}^{L} \frac{f(x, y)}{1+f(x, y)} \\
& d x d y<\left(T_{\mathrm{A}}-T_{0}\right) \int_{-\infty}^{\infty} \int_{0}^{1} f(x, y) d x d y,
\end{aligned}
$$

where the right-hand integral is the maximal value the left-hand integral can attain. With $f(x, y)=e^{\frac{x-L}{L_{\mathrm{PG}}}}$. $e^{-\frac{4}{W_{\mathrm{PG}}^{2}}\left(y-Y_{\mathrm{PG}}\right)^{2}}$, the right-hand integral of Eq. (A3) is

$$
\begin{aligned}
& \left(T_{\mathrm{A}}-T_{0}\right) \int_{-\infty}^{\infty} \int_{0}^{1} f(x, y) d x d y=\frac{\sqrt{\pi} L_{\mathrm{PG}} W_{\mathrm{PG}}}{2 L L_{y}} \\
& \left(1-e^{-\frac{L}{L_{\mathrm{PG}}}}\right)\left(T_{\mathrm{A}}-T_{0}\right) .
\end{aligned}
$$

By substituting the values $\frac{L}{L_{\mathrm{PG}}}=15$ and $4\left(\frac{L_{y}}{W_{\mathrm{PG}}}\right)^{2}=4.8$ (Sect. 3.3), $\langle\Delta T\rangle$ is estimated to be approximately $0.05\left(T_{\mathrm{A}}-T_{0}\right)$ at most. In the experiments, we presented in Sect. $3.3, T_{\mathrm{A}}-T_{0}$ is maximally $2{ }^{\circ} \mathrm{C}$. Hence, the modulation of the equilibrium temperature $T_{0}$ by the throughflow does not exceed $0.1{ }^{\circ} \mathrm{C}$, and can, therefore, be neglected.

Acknowledgements. We have used the PRISM3D Pliocene data from http://geology.er.usgs.gov/eespteam/prism/index.html, the HadISST dataset from http://www.metoffice.gov.uk/hadobs and NOAA_OI_SST_V2 data were provided by the NOAA/OAR/ESRL PSD, Boulder, Colorado, USA, from their Web site at http://www.esrl.noaa.gov/psd/.

Edited by: P. Braconnot

\section{References}

Bonham, S. G., Haywood, A. M., Lunt, D. J., Collins, M., and Salzmann, U.: El Niño-Southern Oscillation, Pliocene climate and equifinality, Phil. Trans. R. Soc. A, 367, 127-156, 2009.

Brierley, C. M. and Fedorov, A. V.: Relative importance of meridional and zonal sea surface temperature gradients for the onset of the ice ages and Pliocene-Pleistocene climate evolution, Paleoceanography, 25, PA2214, doi:10.1029/2009PA001809, 2010.

Brierley, C. M., Fedorov, A. V., Liu, Z., Herbert, T. D., Lawrence, K. T., and LaRiviere, J. P.: Greatly expanded tropical warm pool and weakened Hadley circulation in the Early Pliocene, Science, 323, 1714-1718, 2009.

Cane, M. A. and Molnar, P. H.: Closing of the Indonesian seaway as a precursor to east African aridification 3-4 million years ago, Nature, 411, 157-162, 2001.

Cannariato, K. G. and Ravelo, A. C.: Pliocene-Pleistocene evolution of eastern tropical Pacific surface water circulation and thermocline depth, Paleoceanography, 12, 805-820, 1997. 
Chiang, J. C. H.: The Tropics in Paleoclimate, Annual Rev. Earth Plane. Sci., 37, 263-297, doi:10.1146/annurev.earth.031208. 100217, 2009.

Collins, M.: El Niño- or La Niña climate change?, Clim. Dynam., 24, 89-104, 2005.

Dekens, P. S., Ravelo, A. C., and McCarthy, M. D.: Warm upwelling regions in the Pliocene warm period, Paleoceanography, 22, PA3211, doi:10.1029/2006PA001394, 2007.

Dijkstra, H. A. and Neelin, D.: Ocean-Atmosphere Interaction and the Tropical Climatology. Part II: Why the Pacific Cold Tongue is in the East, J. Climate, 8, 1343-1359, 1995.

DiNezio, P. N., Clement, A. C., Vecchi, G. A., Soden, B. J., and Kirtman, B. P.: Climate Response of the Equatorial Pacific to Global Warming, J. Climate, 22, 4873-4892, doi:10.1175/ 2009JCLI2982.1, 2009.

DiNezio, P. N., Clement, A. C., Vecchi, G. A., Soden, B. J., Broccoli, A. J. amd Otto-Bliesner, B. L., and Braconnot, P.: Paleoceanography, in press, 2011.

Dowsett, H. J. and Robinson, M. M.: Mid-Pliocene equatorial Pacific sea surface temperature reconstruction: a multi-proxy perspective, in: The Pliocene. A vision of Earth in the late twentyfirst century?, 367, 109-126, 2009.

Etourneau, J., Schneider, R., Blanz, T., and Martinez, P.: Intensification of the Walker and Hadley atmospheric circulations during the Pliocene-Pleistocene climate transition, Earth Planet. Sci. Lett., 297, 103-110, doi:10.1016/j.epsl.2010.06.010, 2010.

Fedorov, A., Dekens, P., McCarthy, M., Ravelo, A. C., deMenocal, P. B., Barreiro, M., Pacanowski, R. C., and Philander, S. G.: The Pliocene Paradox (Mechanisms for a permanent El Niño), Science, 312, 5779, doi:10.1126/science.1122666, 2006.

Frankcombe, L. M., Dijkstra, H. A., and von der Heydt, A.: Noise induced multidecadal variability in the North Atlantic: Excitation of normal modes, J. Phys. Oceanogr., 39, 220-233, doi: 10.1175/2008JPO3951.1, 2009.

Galeotti, S., von der Heydt, A., Huber, M., Bice, D., Dijkstra, H. A., Jilbert, T., Lanci, L., and Reichart, G.: Evidence for active ENSO in the late Miocene greenhouse climate, Geology, 38, 419-422, 2010.

Gill, A.: Some simple solutions for heat induced tropical circulation, Quart. J. Roy Meteor. Soc., 106, 447-462, 1980.

Haywood, A. M., Valdes, P. J., and Peck, V. L.: A permanent El Niño-like state during the Pliocene?, Paleoceanography, 22, PA1213, doi:10.1029/2006PA001323, 2007.

Held, I. M. and Soden, B. J.: Robust responses of the hydrological cycle to global warming, J. Climate, 19, 5686-5699, 2006.

Huber, M. and Caballero, R.: Eocene El Niño: Evidence for robust tropical dynamics in the "hothouse", Science, 299, 877-881, 2003.

Jin, F.: An equatorial ocean recharge paradigm for ENSO, 1. Conceptual model, J. Atmos. Sci., 54, 811-829, 1997.

Jin, F. F.: A simple model for the Pacific cold tongue and ENSO, J. Atmos. Sci., 55, 2458-2469, 1998.

Jochum, M., Fox-Kemper, B., Molnar, P. H., and Shields, C.: Differences in the Indonesian seaway in a coupled climate model and their relevance to Pliocene climate and El Nino, Paleoceanography, 24, doi:10.1029/2008PA001678, 2009.

Lunt, D. J., Valdes, P. J., Haywood, A., and Rutt, I. C.: Closure of the Panama Seaway during the Pliocene: Implications for climate and Northern Hemisphere glaciation, Clim. Dynam., 30, 1-18,
2008.

Molnar, P. and Cane, M. A.: El Niño's tropical climate and teleconnections as a blue-print for pre-Ice Age climates, Paleoceanography, 17, 1021, doi:10.1029/2001PA000663, 2002.

Neelin, D. and Dijkstra, H. A.: Ocean-Atmosphere Interaction and the Tropical Climatology. Part I: The Dangers of Flux Correction, J. Climate, 8, 1325-1342, 1995.

Philander, S. G.: El Niño and the Southern Oscillation, Academic Press, New York, 1990.

Philander, S. G. and Fedorov, A.: Is El Niño sporadic or cyclic?, Annu. Rev. Earth Planet. Sci., 31, 579-594, 2003 a.

Philander, S. G. and Fedorov, A. V.: Role of the tropics in changing the response to Milankowitch forcing some three million years ago, Paleoceanography, 18, 1045, doi:10.1029/2002PA000837, $2003 b$.

Ravelo, A., Dekens, P., and McCarthy, M.: Evidence for El Niñolike conditions during the Pliocene, GSA Today, 16, 4-11, 2006.

Ravelo, A. C., Andreasen, D. H., Lyle, M., Olivarez, A., and Wara, M. W.: Regional climate shifts caused by gradual global cooling in the Pliocene epoch, Nature, 429, 263-267, 2004.

Raymo, M. E., Grant, B., Horowitz, M., and Rau, G. H.: MidPliocene warmth: stronger greenhouse and stronger conveyor, Marine Micropaleontology, 27, 313-326, 1996.

Rayner, N., Parker, D., Horton, E., Folland, C., Alexander, L., Rowell, D., Kent, E., and Kaplan, A.: Global analyses of sea surface temperature, sea ice, and night marine air temperature since the late nineteenth century, J. Geophys. Res., 108, 4407, doi:10.1029/2002JD002670, 2003.

Reynolds, R., Rayner, N., Smith, T., Stokes, D., and Wang, W.: An improved in situ and satellite SST analysis for climate, J. Climate, 15, 1609-1625, 2002.

Rickaby, R. and Halloran, P.: Cool La Niña during the warmth of the Pliocene?, Science, 307, 1948-1952, 2005.

Scroxton, N., Bonham, S. G., Rickaby, R. E. M., Lawrence, S. H. F., Hermoso, M., and Haywood, A. M.: Persistent El Nino-Southern Oscillation variation during the Pliocene Epoch, Paleoceanography, 26, PA2215, doi:10.1029/2010PA002097, 2011.

Tziperman, E. and Farrell, B.: Pliocene equatorial temperature: Lessons from atmospheric superrotation, Paleoceanography, 24, PA1101, doi:10.1029/2008PA001652, 2009.

van der Vaart, P. C. F., Dijkstra, H. A., and Jin, F.-F.: The Pacific Cold Tongue and the ENSO Mode: A Unified Theory within the Zebiak-Cane Model, J. Atmos. Sci., 57, 967-988, 2000.

van Oldenborgh, G. J., Philip, S. Y., and Collins, M.: El Niño in a changing climate: A multi-model study, Ocean Sci., 1, 81-95, 2005 ,

http://www.ocean-sci.net/1/81/2005/.

Vecchi, G. A. and Soden, B. J.: Global warming and the weakening of the tropical circulation, J. Climate, 20, 4316-4340, doi:10. 1175/JCLI4258.1, 2007.

von der Heydt, A. and Dijkstra, H. A.: Effect of ocean gateways on the global ocean circulation in the late Oligocene and early Miocene, Paleoceanography, 21, PA1011, doi:10.1029/ 2005PA001149, 2006.

Wara, M., Ravelo, A., and Delaney, M.: Permanent El Niño-like conditions during the Pliocene warm period, Science, 309, 735761, 2005.

Watanabe, T., Suzuki, A., Minobe, S., Kawashima, T., Kameo, K., Minoshima, K., Aguilar, Y. M., Wani, R., Kawahata, H., 
Sowa, K., Nagai, T., and Kase, T.: Permanent El Nino during the Pliocene warm period not supported by coral evidence, Nature, 471, 209-211, doi:10.1038/nature09777, 2011.

Zebiak, S. E. and Cane, M. A.: A model El Niño-Southern Oscillation., Mon. Weather Rev., 115, 2262-2278, 1987. 